\title{
HOW TO INTERCONNECT RESEARCH AND DEVELOPMENT IN EDUCATIONAL PRACTICE
}

\author{
Martin Kaleja, Marek Cetkovský
}

Experts from the Faculty of Public Policies of the Silesian University in Opava, as an implementation team conducted a sociological monitoring of education of preschool children and pupils of compulsory school education in the context of the whole of Czech Republic in the period from June 2014 to September 2015. They implement a research contract where the contracting authority was the Ministry of Education, Youth and Sports of the Czech Republic. The research goal had three basic research planes. The first one involved the implementation of research in the field of literacy among pupils of $3^{\text {rd }}$ and $4^{\text {th }}$ grade at primary schools of all types. The second research plane focused on the readiness of teachers to educate all groups of pupils, and the third dealt with an analysis of educational systems in two selected cities - Sokolov and Krnov.

The project currently implemented is also financially supported from the resources of the European Union. This time, building on the research mentioned, it has a developmental blueprint. Project name: Direct and clear support of the educational inclusion - the question of school, family, neighbourhood (reg. No. 02.3.61/0.0/0.0/15_007/0000239). It represents research-based and desirable support of inclusive policies for the education of primary school pupils at risk of school failure. It addresses the issues of both school and family environment, the issues of counselling and competences of teachers and other staff involved in the solution of these issues. Its main objective is to contribute to the inclusion of marginalised groups of pupils in the education system and to increase their school success rate. Another aim is to cancel animosity and eliminate prejudices and stereotypes through the cooperation of families, schools and other people or entities involved.

The concept is divided into six key activities which are not only dedicated to the family and school environment but also address the competences of teachers, of counselling office staff and of other staff involved in the area of school education. It is possible to consider as a dominant and central innovation concept of the project the fact that the various parts of the key activities were systematically incorporated into the implementation based on long-term monitoring of the issues of educational inclusion of target groups and on the results of research projects on the implementation, but also based on long-term direct pedagogical field practice with the target group and experience based on the European trends toward active support of school inclusion of the affected groups of pupils. 
In the framework of the first key activity (KA1), direct work is conducted with children at risk of school failure. The project staff prepare after-school tutoring or clubs of mathematics and reader literacy. Tutoring takes place at school compounds, or in the form of individual visits in families which naturally engages the children's parents in the process. The targeted tutoring implementation in their home environment, then, naturally affects family life of pupils, enables the staff to talk with the parents and explain to them that the project support is limited in time and that it offers them the opportunity to participate in effecting changes at the school level, as well as among teachers and that some changes must be made by themselves.

Other objectives of the project include the creation of a fully competent environment, using the expansion of the activities of the schools' counselling workplaces by the position of a school special needs teacher and coordinator for school inclusion (KA2). The creation of these positions at specific schools in the context of specific pupils and teachers helps create positive changes that will lead to the autonomy of the teaching staff and to the shaping of the internal inclusive social and physical space of schools. Based on efficient synergy among all members of the school counselling office, the pupils of selected schools are provided with individual non-pedagogical support by means of a classroom assistant (KA3).

To support the effective cooperation among all stakeholders involved in the educational process, the project counts on creating space for joint meetings of teachers and parents, or social workers, (KA4) to develop effective communication and cooperation needed for the positive mood of educational processes both in the family and in school environment, or in the environment of leisure time activities.

In order to guarantee the development of professional competences of teaching staff, further education courses have a firm place in the project, focusing mainly on working with pupils of a different socio-educational characteristic which should be taken into account in the framework of the application of optimal educational strategies.

Currently, almost all the key activity implementations are in full swing. Since the fall of 2016, nineteen primary schools have already joined the project. By the end of 2016, seventy-one tutoring platforms and clubs at elementary schools and seventeen individually designed tutoring programs in families had been implemented. The implementation currently involves eighty-one pedagogues who are taking care of more than three hundred children at risk of school failure. These are not the final figures by far, as the project counts on the participation of at least thirty additional primary schools. In November 2016, a training course to support conducting teaching activities according to the principles of the methodical instruction "Starting Together" took place at the compounds of the Faculty of Public Policies in Opava. Faculty of Public Policies in cooperation with the organization Step by Step CR, CIC [o.p.s.] awarded thirty pedagogues certificates with the accreditation of the Ministry of Education, the Youth and Sports. Other courses are to be started this spring.

By the end of the three-year project implementation, the implementation team will evaluate the inclusiveness of at least fifty involved primary schools from the vicinity of 
Opava, Krnov, Ostrava and Vsetin whose results will be higher than at the very beginning. Thanks to the implementation of the whole concept of the project, significant changes of both quantitative and qualitative nature in school success rates are expected for a majority of Roma primary school pupils involved. The training programs will support education processes based on the individual principle, ensure the development of key competences and of both reading and mathematical literacy of pupils. In a systemic way, the teaching staff will be led to the formation of an inclusive environment both on the social and physical level so that they can perform this activity independently. Using the training courses designed, the teachers will become familiar with practical issues of school inclusions both in wider and narrower educational intents and always with substantive relevance to the learners themselves, the social environment in which they live and grow up, and to the people who have influence on the processes of their socialisation.

\section{Authors}

doc. PhDr. et PhDr. Martin Kaleja, CSc.

Faculty of Public Policies, Silesian University in Opava

Bezručovo nám. 885/14, 74601 Opava, The Czech Republic

martin.kaleja@fvp.slu.cz

Mgr. Marek Cetkovský

Faculty of Public Policies, Silesian University in Opava

Bezručovo nám. 885/14, 74601 Opava, The Czech Republic

marek.cetkovsky@fvp.slu.cz 